\title{
Assistência de enfermagem perioperatória: ensino em cursos de enfermagem
}

THE TEACHING OF THE PERIOPERATORY NURSING ASSISTANCE IN UNDERGRADUATE COURSES IN NURSING

ENSEÑANZA DE ENFERMERÍA PERIOPERATORIA EN LOS CURSOS DE PRE GRADO EN ENFERMERÍA

\author{
Maria do Carmo Querido Avelar', Arlete Silva ${ }^{2}$
}

1 Enfermeira, Professor Titular I da Universidade Guarulhos - UnG - CEPPE

-Centro de Pós Graduação Pesquisa e Extensão. carmoav@uol.com.br

2 Enfermeira, Professora Doutora da UnG.

arlsilva@uol.com.br

\begin{abstract}
RESUMO
Buscou-se no presente estudo, retratar a realidade do ensino da assistência de enfermagem perioperatória, analisando e delineando suas tendências entre docentes de cursos de graduação em enfermagem que ministram esse conteúdo. A assistência de enfermagem perioperatória como processo realizado por profissionais de enfermagem, em uma fase específica de atenção ao paciente, frente ao procedimento anestésico-cirúrgico, envolve estratégias e orientações expressas na práxis do enfermeiro. Aqui o ensino da assistência de enfermagem perioperatória, como atividade dinâmica das ações dos docentes de Enfermagem em Centro Cirúrgico, desenvolvida num processo coletivo, emerge como práxis ritual no mundo do sistema, da razão técnica instrumental, distanciando-se do entendimento consensual, da razão comunicativa e do fomento às alternativas voltadas à práxis social/emancipatória.
\end{abstract}

\section{DESCRITORES}

Enfermagem perioperatória (educação).

Enfermagem perioperatória (tendências).

\section{ABSTRACT}

In the present study, the authors describe the reality of the perioperatory nursing assistance, analyzing and outlining its trends among professors of undergraduate courses in Nursing that teach this subject. Perioperatory nursing assistance, as a process carried out by nursing professionals, in a specific phase of attention to the patient prior to the anesthetic-surgical procedure, involves strategies and orientations that are expressed in the nurse's praxis. In this study, the teaching of perioperatory nursing assistance, as a dynamic activity of the actions of the professors of Nursing in the Surgical Center, developed in a collective process, emerges as a ritual praxis of the system's realm, of the instrumental technical reason, moving away from the consensual understanding, from the communicative reason and from the encouragement to the alternatives directed towards the social/emancipatory praxis.
\end{abstract}

\section{KEY WORDS}

Perioperative nursing

(education).

Perioperative nursing (trends).

\section{RESUMEN}

En el presente estudio se buscó retratar la realidad de la enseñanza de la asistencia de enfermería perioperatoria, analizando y delineando sus tendencias entre los docentes de enfermería perioperatoria. Como proceso realizado por los profesionales de enfermería en una fase específica de atención al paciente frente al procedimiento anestésico-quirúrgico, involucra estrategias y orientaciones expresadas en la praxis del enfermero. Se puede concluir que la enseñanza de la asistencia de enfermería perioperatoria, como actividad dinámica de las acciones de los docentes de Enfermería en Centro Quirúrgico, desarrollada en un proceso colectivo, emerge como praxis ritual en el mundo del sistema, de la razón técnica instrumental, distanciándose del entendimiento consensual de la razón comunicativa y de fomento de alternativas relativas a la praxis social/ emancipadora.

\section{DESCRIPTORES}

Enfermería perioperatoria (educación).

Enfermería perioperatoria (tendencias). 


\section{INTRODUÇÃO}

O atual modelo de ensino tem pouco contribuído para a formação do profissional crítico, criativo, reflexivo e competente. O predomínio da compartimentalização e do cunho tecnicista do ensino, vem privilegiando a memorização e a reprodução do saber, dificultando e mesmo inviabilizando a agregação da dimensão ético-política ao processo de ensino. A superação da dimensão técnica permite a dotação do sentido social num ensino contextualizado, voltado a uma prática transformadora, na qual são revistas as concepções, intervenções, enfim, a prática profissional. Esta possibilidade pressupõe a desconstrução de estereótipos e pré-concepções, problematizando o fenômeno, reconhecendo sua configuração no contexto social ${ }^{(1)}$.

A proposição de conceitos e modelos que explicitam valores, tentando responder a uma ordem de questões para além da tecnologia, tornouse um modo de produzir enfrentamentos dos limites do conhecimento. $\mathrm{O}$ saber em enfermagem é analisado em bases pragmáticas e empíricas, fazendo-se necessário ir além, na busca de uma análise de suas bases filosófico/ideológicas. Como fenômeno a ser estudado tem-se que buscar referências no conhecimento produzido, exigindo capacidade para relacioná-lo às práticas gerais e às práticas específicas deste saber. O conhecimento emerge pela ação de forças de diferentes características, sejam sociais, culturais, epistemológicas, numa integração de saberes. Esta situação vem exigir novas responsabilidades e a necessidade de reorganização de conteúdos, abrindo espaços de discussão das práticas existentes ${ }^{(2)}$.

Há alguns anos tem-se uma preocupação constante sobre o ensino da assistência de enfermagem perioperatória em suas diferentes formas de implementação nos cursos de graduação em enfermagem. Neste trabalho busca-se conhecer uma situação, demonstrando a relevância das suas características, identificando-a como um produto político-pedagógico voltando-se para a possibilidade de retratar a realidade nela expressa. A assistência de enfermagem perioperatória caracterizase por ser um processo realizado numa fase muito específica da atenção ao paciente, frente ao procedimento anestésico-cirúrgico, no sistema normativo e organizativo do Centro Cirúrgico, no qual os profissionais de enfermagem ampliam suas áreas de domínio, incluindo a responsabilização por outros serviços que são aí realizados, impondo-lhes a fragmentação do seu trabalho, de modo a confundi-los sobre sua real necessidade ${ }^{(3)}$.
A assistência de enfermagem perioperatória, voltada à satisfação das necessidades dos indivíduos na fase anestésico-cirúrgica vem carecendo de uma abordagem reflexiva quanto ao seu processo de ensino. O processo de ensino diante das tendências decorrentes do mundo globalizado, impõe a necessidade de rumos definidos de formação que conduzam à competência, em formas diferenciadas de preparo dos profissionais, para o ingresso na área do trabalho. Neste sentido, tem-se impulsionado a capacitação profissional, com mudanças de conduta, passando a universidade, de "locus" destinado ao repasse de conhecimentos para incluir espaços mais amplos, tanto internos quanto externos, onde se operam processos pedagógicos ${ }^{(4)}$.

A produção do conhecimento também assume outra conotação no processo de formação do aluno voltado à realidade concreta, contemplando os contextos, histórico, social, econômico, cultural e suas múltiplas determinações. Assim, o conhecimento vai expressar uma nova abordagem político-sociológica, voltada à solução de problemas, mudanças de contexto e de qualidade de vida, vinculados ao processo de transformação da realidade. Configurando novos redimensionamentos, concilia interesses profissionais em diferentes tendências, ancoradas em projetos político-pedagógicos, centrados em pressupostos e objetivos de uma política acadêmica diferenciada ${ }^{(4)}$. Com isto entende-se imprescindível a caracterização das tendências, nas quais se pauta o processo ensinoaprendizagem da assistência de enfermagem perioperatória.

A Disciplina Enfermagem em Centro Cirúrgico constitui a área de interesse onde se concentram as prerrogativas para compreensão das características da realização do ensino da assistência de enfermagem perioperatória. Sua clareza possibilitará estabelecer relações voltadas aos interesses e problemas que mobilizam nossa atenção neste estudo. Para delinear o objeto, o ensino da assistência de enfermagem perioperatória, foi necessário a obtenção de informações e um trabalho de coordenação da realidade empírica, cujas condições são, entre outras, o traçado de uma moldura na qual o objeto se situa ${ }^{(5)}$. Conhecer como é realizado o ensino da assistência de enfermagem perioperatória, em cursos de graduação em enfermagem incluiu conhecer a Disciplina Enfermagem em Centro Cirúrgico e o perfil do docente responsável. Neste estudo partiu-se da crença que o ensino da assistência de enfermagem perioperatória congrega as possibilidades de expansão das responsabilidades dos profissionais numa visão estético-expressiva-
Assistência de enfermagem perioperatória: ensino em cursos de enfermagem 
Maria do Carmo Q. Avelar Arlete Silva comunicativa. Na dinâmica das ações dos docentes de enfermagem em centro cirúrgico, o ensino da assistência de enfermagem perioperatória vem a ser um fator de contribuição para o estudo das formas de sua problematização e conseqüentes soluções.

\section{BASE REFERENCIAL DO ESTUDO}

O presente estudo tem como base a teoria habermasiana. Nesta teoria a dialética e hermenêutica integram o projeto que Habermas desenvolveu com a utilização sistemática do paradigma da comunicação - a teoria da ação comunicativa. Nela são focalizados os conceitos de racionalidade comunicativa em oposição à racionalidade instrumental, o mundo da vida e o mundo do sistema, num conceito dialético de sociedade $^{(6-9)}$

Na teoria da ação comunicativa, o mundo da vida constitui o saber intuitivo implícito da práxis comunicativa do dia-a-dia no qual vivemos, agimos e falamos com os outros, parecendo sempre como insuficiente, rudimentar se comparado com o saber científico explícito. Para tornar explícito esse saber implícito, de sujeitos que falam, agem, pensam e fazem ciências e arte, é necessário identificar as estruturas do mundo da vida. É preciso colocar o mundo da vida em questionamento para captar a razão de ser de seus objetos, no momento em que o contexto vital objetivo esteja enfrentando ameaças com o surgimento de obstáculos, desafios, problemas, dificuldades coletivas. Neste momento, o mundo da vida mostra a sua compreensibilidade, situação na qual pequena parcela do saber, desprende-se de tradições complexas e se transformam em saber explícito. Habermas configura o paradigma da comunicação como aquele que durante seu desenvolvimento histórico é obrigado a entender-se junto com os outros sujeitos, num enfoque de entendimento intersubjetivo, entre sujeitos capazes de falar e $\operatorname{agir}^{(9)}$.

Habermas $^{(10)}$ distingue dois tipos básicos de ação humana, o agir instrumental e o agir comunicativo. $\mathrm{O}$ agir instrumental orienta-se por regras técnicas decorrentes de um saber empírico, onde predomina o modelo de ação técnica, estratégica, ou seja, a práxis ritual. $\mathrm{O}$ agir comunicativo, orientado para o entendimento, constitui uma interação mediada pela linguagem, em mundos da vida que se interpenetram e se interligam ${ }^{(9)}$, caracterizando a práxis social, emancipatória.

O conceito de mundo da vida é constituído pelas estruturas simbólicas: cultura, sociedade, sujeito, reproduzidas através das ações voltadas ao entendimento consensual. O desmoronamento do mundo da vida coloca em cena o mundo do sistema. Assim, a sociedade pode ser interpretada como sendo mundo vital - da razão comunicativa e mundo do sistema, da razão técnica instrumental ${ }^{(9)}$.

\section{OBJETIVOS}

Diante da proposta de se conhecer as tendências do ensino da assistência de enfermagem perioperatória, estabeleceu-se como objetivo para este estudo:

- levantar dados junto aos docentes envolvidos no processo de ensino da Disciplina Enfermagem em Centro Cirúrgico e do conteúdo sobre assistência de enfermagem perioperatória;

- realizar análise utilizando o referencial habermasiano e

- delinear as tendências expressas nesse processo.

\section{METODOLOGIA}

Realizou-se este estudo entre enfermeiros docentes da Disciplina Enfermagem em Centro Cirúrgico, responsáveis em ministrar conteúdos sobre o ensino da assistência de enfermagem perioperatória, em cursos de graduação em enfermagem, na cidade e região metropolitana de São Paulo, no período de maio a outubro de 2002.

Em observância às Diretrizes da Resolução $n^{\circ}$ 196/96 do Conselho Nacional de Saúde o projeto do presente estudo foi encaminhado ao Comitê de Ética em Pesquisa da instituição do pesquisador. Após sua aprovação foi solicitada a autorização para coleta de dados ao Chefe/Coordenador da Disciplina Enfermagem em Centro Cirúrgico, anexada ao resumo do projeto e encaminhados com o instrumento de coleta de dados e o Termo de Consentimento Livre e Esclarecido, em duas vias.

Foram incluídos os docentes que consentiram participar do estudo e que coordenavam ou ministravam conteúdos relativos ao ensino de enfermagem em centro cirúrgico, em cursos de graduação em enfermagem. Fez-se um levantamento, junto aos órgãos específicos, dos cursos de graduação em enfermagem em funcionamento na cidade de São Paulo e nos municípios da Grande São Paulo, conseguindo estabelecer contacto com 24 deles. 
Foram então enviados aos docentes responsáveis, para fornecerem os dados informativos sobre o ensino da assistência de enfermagem perioperatória, os questionários e envelopes selados para o seu retorno. Após dois meses de espera e com o retorno de apenas 6 (seis) instrumentos, foi feito novamente o seu envio, obtendo-se como amostra o total de 10 (dez) instrumentos.

O instrumento foi construído em duas partes, sendo a primeira sobre a caracterização dos participantes e contendo questões relativas à sua posição na Instituição; a segunda parte incluiu as informações dos docentes quanto ao ensino da assistência de enfermagem perioperatória.

Para o alcance do objetivo do estudo a abordagem quantitativa/qualitativa foi a opção que pareceu melhor orientar as questões explicativas da realidade do ensino da assistência de enfermagem perioperatória. $\mathrm{Na}$ abordagem quantitativa os dados foram coletados e tratados estatisticamente, utilizando-se percentuais simples. $\mathrm{Na}$ abordagem qualitativa buscou-se incorporar o significado e a intencionalidade inerentes às informações. A metodologia proposta para este estudo orientouse pelo enfoque do agir comunicativo habermasiano. Buscou-se conhecer as informações expressas nos depoimentos da realidade de cada participante, em suas ações com seus significados. Esses significados são referidos como cultura, norma, compreensão da realidade social, definição de situações, ideologias, crenças, visão de mundo. As significações são transcomportamentais, no sentido de não apenas descrever o comportamento mas definí-lo, justificá-lo e interpretá-lo ${ }^{(11)}$.

As atividades do estudo desenvolveram-se basicamente em quatro momentos: o primeiro teve como objetivo a caracterização do perfil do grupo participante; o segundo situou o conteúdo identificado sobre o ensino da assistência de enfermagem perioperatória, em termos de análise de dados relevantes dessa realidade. No terceiro momento buscou-se o aprofundamento da análise do material destacado, identificando enfoques prioritários da prática do ensino da assistência de enfermagem perioperatória. O quarto momento foi o da síntese do processo, considerando as seguintes questões: - qual o pensamento norteador que emerge dessa análise; como utilizar as representações que emergiram e que contribuições poderiam trazer para o ensino da assistência de enfermagem perioperatória.

Após organizar as informações procedeu-se à leitura exaustiva desse material, buscando apreen- der seu conteúdo, em termos de estruturas de relevância, idéias centrais e expectativas sobre o ensino da assistência de enfermagem perioperatória estabelecendo e confrontando suas relações. Após compreensão dos conteúdos e informações contidas no material, em termos de unidades de significados, os temas foram referenciados por núcleos de pensamento e posteriormente reagrupados em categorias, realizando-se a análise final ${ }^{(5)}$.

\section{CENÁRIO DO ESTUDO}

Os enfermeiros docentes de centro cirúrgico que responderam os questionários estavam alocados em universidades: pública (1 - 10\%), privada (3 -30\%) e instituições isoladas privadas (6 $60 \%$ ). Caracterizavam-se por serem mulheres, solteiras $5(50 \%)$ e casadas $5(50 \%)$ e idade entre 38 a 58 anos. Entre os docentes, 7 (70\%) coordenavam especificamente a Disciplina Enfermagem em Centro Cirúrgico; 3 (30\%) coordenavam o conteúdo de enfermagem em centro cirúrgico inserido na Disciplina Saúde do Adulto. As instituições estavam localizadas na cidade de São Paulo 5 (50\%) e na sua região metropolitana 5 (50\%).

Referiram tempo de docência em Enfermagem entre 2 a 10 anos (3 - 30\%) e entre 10 a 20 anos (7 $70 \%$ ); quanto ao tempo de docência em enfermagem em centro cirúrgico, especificamente, foi de 2 -10 anos (3-30\%) e de $10-20$ anos (7 - 70\%).

Os Cursos de Graduação em Enfermagem, com carga horária média entre 4000 horas e todos (10 $100 \%$ ) com duração de 4 anos (8 semestres) letivos, ministravam o conteúdo de enfermagem em centro cirúrgico, tendo como pano de fundo a Disciplina Saúde do Adulto (3 - 30\%) e a Disciplina Enfermagem em Centro Cirúrgico (e Centro de Material) (7 - 70\%), ministradas no $4^{\circ}$ semestre (2 $20 \%)$; no $5^{\circ}$ semestre (6 - 60\%) e no $7^{\circ}$ semestre (2 $-20 \%)$. A carga horária teórica em enfermagem em centro cirúrgico variou entre $30(8-80 \%)$ e 72 horas $(2-20 \%)$ e a prática entre 60 horas $(6-60 \%)$ e 90 horas $(4-40 \%)$.

Os conteúdos sobre a assistência de enfermagem perioperatória, nos aspectos teóricos, vinham sendo abordados pelos docentes dos cursos nos seguintes momentos: - no bloco teórico da Disciplina Enfermagem em Centro Cirúrgico (7 - 70\%) e no seu desenvolvimento (3-30\%). Nos aspectos práticos, a abordagem do conteúdo sobre assistência de enfermagem perioperatória foi durante $o$ estágio em centro cirúrgico (5 - 50\%); durante ensino clínico $(2-20 \%)$ e em visitas pré e pós-operatórias (3 - 30\%).
Assistência de enfermagem perioperatória: ensino em cursos de enfermagem 
Maria do Carmo Q. Avelar Arlete Silva
Quanto ao número de docentes do curso que abordavam este conteúdo, em teoria foi referido ser, em média, um professor, em 8 - $80 \%$ dos cursos e dois ou mais em 2 - 20\% deles. Na prática, a abordagem era feita por um professor em 9 - 90\% dos cursos e por até 3 professores em 1 - 10\%.

A relação numérica entre professor/aluno no ensino da assistência de enfermagem perioperatória foi de $7-8$ alunos (em 8 - 80\% dos cursos) e 10 alunos (em 2 - 20\% dos cursos) por docente.

\section{ANÁLISE E DISCUSSÃO DOS RESULTADOS}

Nesta análise buscou-se ultrapassar a incerteza sobre a seguinte indagação: - "o que percebo nos conteúdos expressos pelos docentes estará realmente contido? minha leitura é válida?" Para ultrapassar o olhar imediato e espontâneo, tentou-se atingir a compreensão das significações, buscando a descoberta de conteúdos em estruturas latentes e pela integração num quadro de referência no qual se inseriam as informações ${ }^{(3)}$. Os significados manifestos e latentes do material coletado foram explicitados utilizandose a hermenêutica-dialética ${ }^{(9)}$, não apenas como uma tecnologia de interpretação mas um caminho do pensamento.

Sendo o objeto do estudo o ensino da assistência de enfermagem perioperatória e considerando seus objetivos, ementa, conteúdo e referência bibliográfica, a análise voltou-se para o caráter das intenções contidas nos aspectos que vão além das manifestações estereotipadas, assegurando o desvelamento do processo em estudo $^{(12)}$. Procedeu-se então à descrição do material coletado, levando em consideração os diferentes contextos, tendo nesta fase tentado captar o seu significado, encaminhando-se para a formação de agrupamentos por afinidade; análise e interpretação do conteúdo expresso, com base na teoria do agir comunicativo ${ }^{(3)}$. A apreensão das representações conduziu ao estabelecimento de duas categorias - a compreensão e a superação. Na categoria compreensão as representações analisadas levaram-nos a considerar a habilidade de se ajustarem a conteúdos e temas da assistência de enfermagem perioperatória.

Nos objetivos da disciplina Enfermagem em Centro Cirúrgico foram explicitadas as intenções de identificar, caracterizar, conhecer: aspectos físicos e instalações das Unidades de Centro Cirúrgico (UCC), Centro de Material Esterilizado
(CME), Recuperação Pós Anestésica (RPA) e aspectos organizacionais da UCC, Serviço de RPA e CME, voltados aos insumos materiais, equipamentos e dimensionamento do pessoal. Durante a assistência emergiram os tipos, fases, complicações/riscos do processo anestésico-cirúrgico, capacitação e habilidades a serem alcançadas; competências a serem atingidas na circulação de salas de operações; domínio dos princípios de esterilização, desinfecção e limpeza; identificação das fases de reprocessamento e reesterilização de materiais/artigos; manutenção da sua esterilidade e práticas em central de material esterilizado. A assistência de enfermagem perioperatória aparece como uma proposta para sistematizar a assistência de enfermagem em centro cirúrgico. Na assistência de enfermagem ao paciente em fase perioperatória as dificuldades de sua operacionalização denotam a realidade experienciada pelos docentes, que deixam transparecer seus limites de ação expressos em relação à estreita autonomia da sua práxis.

Das ementas da Disciplina Enfermagem em Centro Cirúrgico abstraíram-se atividades previstas e/ou determinadas, no sentido de propiciarem a instrumentalização do aluno com conhecimentos específicos para o trabalho em Centro Cirúrgico e para as práticas em Centro de Material. As ações/atividades específicas configuraram a circulação em Sala de Operações e os procedimentos assépticos concernentes à instrumentação cirúrgica. $\mathrm{O}$ ensino teórico-prático da sistematização da assistência de enfermagem perioperatória, relegado a segundo plano, contrastou-se com a situação da valorização das tarefas administrativas do profissional, na prática. O docente de Enfermagem em Centro Cirúrgico, em relação à sua atuação, tem enfrentado muitos dilemas e conflitos pessoais e organizacionais, dificultando sua contribuição na superação dessa situação.

Os conteúdos da Disciplina Enfermagem em Centro Cirúrgico agruparam-se em aspectos organizacionais, processuais e comportamentais abordando itens como: circulação de SO, instrumentação de $\mathrm{SO}$, procedimentos antimicrobianos; procedimentos técnicos relativos à anestesia, hemostasia, posições e instrumentais da SO; riscos de infecção do paciente cirúrgico; repercussões do trauma anestésico-cirúrgico; tratamentos cirúrgicos, terminologia, tempos cirúrgicos, degermação, ambiente cirúrgico e bioengenharia; reconhecimento e reprocessamento de materiais. Na compreensão dessa abordagem emergem as intenções relativas ao domínio da 
instrumentação tecnológica, como privilégio dos mais desenvolvidos, atualizados e modernos, convencendo-se de estar no mundo que lhe é próprio, pela imagem da realidade empírica. Subsiste aí o reconhecimento de um conjunto de comportamentos adequados à hegemonia das condições vigentes; a ideologia de que as coisas são o que são e não poderiam ser diferentes do que são ${ }^{(13)}$.

A tendência para dominar o conhecimento instrumental tecnológico confronta-se com o desafio da busca da qualidade política do ensino da assistência de enfermagem perioperatória em centro cirúrgico. $\mathrm{O}$ ensino da assistência de enfermagem perioperatória sustenta as intenções de dirimir a acentuada desarticulação entre propostas de ensino e a prática. No desenvolvimento dos programas não são encontrados nem esboçados espaços de discussão, nichos privilegiados de formação crítica e de fomento às alternativas de posicionamento político.

Quanto aos objetivos do conteúdo da assistência de enfermagem perioperatória, envolvem intenções para o alcance da capacitação dos alunos na prestação dessa assistência utilizando a sistematização, num quadro estereotipado de ações. Expressam a falta da adequação das propostas frente às prioridades, recursos e condições apropriadas para o alcance de ações político-críticas e interpretação da realidade social com discernimento ideológico.

Os métodos e técnicas referidas para desenvolver o conteúdo foram leituras de artigos, aulas expositivas, visitas pré e pós operatórias, recepção, assistência e avaliação do paciente na SO; acompanhamento e assistência em Serviço de RPA; encaminhamento para a Unidade de Internação, apresentando estudos de caso e seminários. Num processo de análise percebe-se a fragilidade da proposta revelada numa visão que deixa transparecer a ausência de contraposição ao esquema rotineiro e sistemático do trabalho, conduzindo à alienação em torno da questão da formação. As ações referidas vislumbram uma falsa segurança e êxito do ensino, evidenciando a forte interferência do tecnicismo, do mundo do sistema que vem garantindo o desenvolvimento do trabalho voltado para seus fins.

A indicação bibliográfica, uniforme, repetitiva e calcada no tecnicismo, deixa arraigada a compreensão inadequada do desenvolvimento do ensino da assistência de enfermagem perioperatória, numa visão ingênua e ilusória, sem possibilidade de questionamentos, encobrindo a falha de formação da consciência crítica.
Neste contexto é a superação inviabilizada pela falta de discernimento ideológico no ensino da assistência de enfermagem perioperatória, conduzindo à alienação em torno de direitos e deveres, perpetuando a aceitação da situação hegemônica das condições vigentes.

\section{CONCLUSÕES}

Após análise pode-se concluir que o ensino da assistência de enfermagem perioperatória destaca-se por ser biologizante, tecnicista, numa situação de difícil vislumbre de um compromisso político-ideológico. A preocupação com a mudança não emerge das representações dos docentes e a contribuição de propostas de inovação do ensino e da prática de Enfermagem em Centro Cirúrgico, na perspectiva de construção de novos modelos de ensino e assistência, não surgiu como esperado. As tendências contraditórias desse processo no âmbito do entendimento de processos formais de aprendizagem ${ }^{(9)}$, situam-se em estruturas voltadas ao ritual caracterizando a práxis ritual.

Este estudo contribui para maior visibilidade das perturbações de consenso no ensino especificamente da assistência de enfermagem perioperatória. Manifestada em contextos de mundos diferentes: - o mundo da vida da enfermagem, com aparente consenso em esforços de lideranças para a mobilização e criação de propostas políticopedagógicas e o mundo sistêmico da enfermagem, normatizado em diretrizes, normas, estruturas ideológicas arraigadas, onde predominam as ações isoladas de docentes de cursos de enfermagem, negando a possibilidade de expansão das suas responsabilidades profissionais na dimensão estético-expressiva-comunicativa.

\section{CONSIDERAÇÕES FINAIS}

O ensino da Enfermagem em Centro Cirúrgico e da assistência de enfermagem perioperatória retrata uma concepção pedagógica tradicional e hegemônica, pois não é percebida a intenção de propostas comprometidas com mudanças, nem manifestações da sua superação. Os programas nos objetivos, ementas, conteúdos e referências bibliográficas mantêm-se fiéis a um esquema tecnicista. Enquadram-se no mundo do sistema e não no mundo da vida da enfermagem, sobressaindo sua vinculação à racionalidade instrumental, em oposição à racionalidade comunicativa que conduz à prática da emancipação, da formação da identidade dos sujeitos, situada historicamente na práxis social.
Assistência de enfermagem perioperatória: ensino em cursos de enfermagem 
Maria do Carmo Q. Avelar Arlete Silva
Correspondência: Maria do Carmo Q. Avelar Rua Fortunato, 208,

Ap. 72, Higienópolis - São Paulo

CEP: 01224-030 - SP
As formas de racionalidade tecnológica, científica, econômica e burocrático-administrativa predominantes, infiltradas nas estruturas vitais cultura, sociedade e sujeito, conduzem a alterações do mundo da vida, fragmentando-o, levando ao problema de reificação, ou seja, à demolição de elementos não regeneráveis da tradição cultural $^{(7)}$.

Os docentes, nas suas representações, prendem-se, de forma geral, aos aspectos da tecnologia, permitindo um desencaixe progressivo entre o mundo da vida e mundo do sistema, rompendo o equilíbrio entre imperativos formais e funcionais do sistema e as normas e valores éticos da ação humana. $\mathrm{O}$ mundo do sistema integra aspectos técnicos, econômicos, burocrático-administrativos e permite apenas a vinculação ao funcionalismo estrito com enfoque no conhecimento dos objetos e sua dominação.

O ensino da assistência de enfermagem perioperatória como atividade expressiva das ações dos docentes de enfermagem em centro cirúrgico e compreendido como prática social determinada e desenvolvida num processo coletivo, é um processo negado por suas contradições distanciando-se do entendimento consensual, da razão comunicativa.

Contudo, a tentativa de compreensão das determinações do mundo da vida e do mundo do sistema no ensino da assistência de enfermagem perioperatória vem reforçar a importância da busca de propostas participativas enfocadas no seu processo operativo. A implementação da estratégia de rediscussão e redistribuição do poder, utilizando a intermediação de saberes e práticas solidárias de mundos diferentes, da racionalidade instrumental e da racionalidade comunicativa, sem o domínio de um sobre o outro, poderá possibilitar o entendimento voltado à transformação, numa interpretação que conduza ao redirecio-namento do ensino, configurando a abertura de espaços interpretativos, postos ao alcance de propostas participativas na criação de soluções próprias, visualizadas numa práxis emancipatória.

\section{REFERÊNCIAS}

(1) Alves CD. O agir comunicativo e as propostas curriculares da enfermagem brasileira. Pelotas: Universitária; 2000.

(2) Leopardi MT. Teorias de enfermagem: instrumentos para a prática. Florianópolis: Papa-Livros; 1999.

(3) Avelar MCQ. A prática do enfermeiro de Centro Cirúrgico. São Paulo. [tese] São Paulo (SP) Escola de Enfermagem da USP; 1995.

(4) Moreira LC. Integração docente-assistencial: elaboração da política de integração entre a Faculdade de enfermagem e hospital. Col Enferm1999; 2:11740 .

(5) Minayo MCS. O desafio do conhecimento: pesquisa qualitativa em saúde. São Paulo: Hucitec; 1994.

(6) Freitag B. A teoria crítica: ontem e hoje. $3^{\text {a }}$ ed. São Paulo: Brasiliense; 1990
(7) Habermas J. Um perfil filosófico-político. Novos Estud Cebrap 1987; 18:77-102.

(8) Habermas J. Teoria de la acción comunicativa: complementos y estudios previos. Madrid: Catedra; 1989.

(9) Siebeneichler FB. Jürgen Habermas: razão comunicativa e emancipação. Rio de Janeiro: Tempo Brasileiro; 1989.

(10) Habermas J. Passado como futuro. Rio de Janeiro: Tempo Brasileiro; 1993.

(11) Lofland J, Lofland LH. Analysing social settings - a guide to qualitative observation. $2^{\text {nd }} \mathrm{ed}$. California: Wadsworth; 1984.

(12) Demo P. Avaliação qualitativa. $3^{a}$ ed. São Paulo: Cortez; 1991.

(13) Horkheimer M, Adorno T. Temas básicos de sociología. São Paulo: Cultrix; 1973.

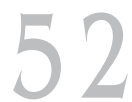

Rev Esc Enferm USP $2005 ; 39(1): 46-52$. 